\title{
LCD applications of thin-crystal-film polarizers
}

\author{
Y. Bobrov, O. Kuchenkova, \\ M. Kouznetsov, P. Lazarev, \\ A. Manko, V. Nazarov, \\ N. Ovchinnikova, M. Paukshto, \\ P. Protsenko, S. Remizov,
}

\begin{abstract}
We have developed a new technique for the production of thin crystal film (TCF) by deposition, molecular alignment, and the drying of water-based lyotropic-liquid-crystal (LLC) materials. TCF exhibits high optical anisotropy and birefringence. This paper presents liquid-crystal-display (LCD) applications and opportunities for TCF plastic sheet polarizers, retarders, and color-correction films as well as LCD designs with TCF internal polarizers.
\end{abstract}

Keywords - Polarizer, LCD, thin crystal film, retarder, color correction film, internal polarizer.

\section{Introduction}

Thin-crystal-film (TCF) technology ${ }^{1-6}$ is based on the crystallization of self-assembling disk-shaped molecules. TCF is produced by the deposition of water-based lyotropic liquid crystal (LLC) formed by rod-like supramolecules made of organic sulfonic acids. Supramolecules, which have a columnar structure with an aspect ratio of more than 100, are formed by the interaction between disk-shaped aromatic conjugated molecules. ${ }^{7,8}$ Within a certain temperature and concentration range, the supramolecules form a liquid-crystal phase in water. A rheological behavior associated with the liquid-crystal state is essential in the processing of these materials into a crystal structure with desirable polarizing properties. The material in this LLC state can be coated onto a glass or plastic substrate with an orienting shear stress to form anisotropic TCF.

The strong anisotropy of the refraction and absorption indices ${ }^{9-11}$ makes TCF attractive for applications in liquidcrystal-displays (LCDs) and organic light-emitting devices (OLEDs). ${ }^{1-6,12-15}$ The first industrial applications of TCF technology include plastic film polarizers, retarders, and color-correction films for the flat-panel-display (FPD) market. We discuss in this paper the optical and color characteristics of the first film products as well as their LCD applications.

TCF technology opens new opportunities for LCD design with internal polarizers. We present the optical and electro-optical performance of pre-production prototype TN-LCD cells with internal TCF polarizes.

\section{TCF materials and coating technique}

The initial selection of the material for TCF fabrication is determined by the presence of $\pi$-conjugate bonds in the aromatic conjugated compounds. Materials for TCF manufacture are based on water-soluble sulfonic salts of aromatic compounds with $\pi$-conjugated bonds ${ }^{1-3}$ and their mixtures. We produced LLC compositions with different optical characteristics: neutral N015, blue-violet V008, yellow Y104, and colorless C001.

TCF can be produced by direct deposition of LLC material onto a variety of substrates by different existing commercial wet-coating methods, such as slot die extrusion, offset gravure, Mayer rod, and doctor blade. The common factor in every method is the application of a uniform shear force in the coating process to produce a thin and uniform material layer. The shear force during the coating process provides the necessary alignment of supramolecules in the liquid layer. The long rod structures align along the shear force direction in a wet layer that is about $10 \mu \mathrm{m}$ thick. While drying, the layer crystallizes to a sub-micron-thick TCF functional layer with dichroic molecules aligned over the entire coated surface. A uniform wet coating of $5-15 \mu \mathrm{m}$ thick ${ }^{1-3,12}$ produces TCFs with a range of thicknesses from 100 to $1000 \mathrm{~nm}$.

The TCF properties are defined to a great extent by their coating technology. The preferable deposition methods are slot-die or Mayer rod. Optiva, Inc., and Nakan Corp. have developed a coating process and equipment based on a Mayer-rod shearing technique. ${ }^{16-18}$ Sony Magnetic Products of America (SMPA) has begun production of TCF plastic-sheet polarizers and retarders using a slot-die coating method $^{19}$ on a roll-to-roll process.

Both coating methods provide the same optical performance of the finished polarizing films. The main advantages of the slot-die method over the Mayer-rod coating technique are (1) the option to form large-area crystalline films; (2) TCF coating in a roll-to-roll process on a highspeed coating line (125 ft/min); (3) good reproducibility; (4) high uniformity; and (5) wide thickness range starting at 100 $\mathrm{nm}$. The slot does not touch the substrate, which allows the avoidance of damage to the plastic surface. ${ }^{20}$ The roll-to-roll

Revised version of a paper presented at the 12th International Symposium on Advanced Display Technologies (ADT '03) held August 25-28, 2003, in Korolev, Moscow Region, Russia.

The authors are with Optiva, Inc., 377 Oyster Point Blvd. \#13, South San Francisco, CA 94080; telephone 650/616-7600, fax -7602, e-mail: YBobrov@optivainc.com.

(c) Copyright 2004 Society for Information Display 1071-0922/04/1202-00001\$1.00 


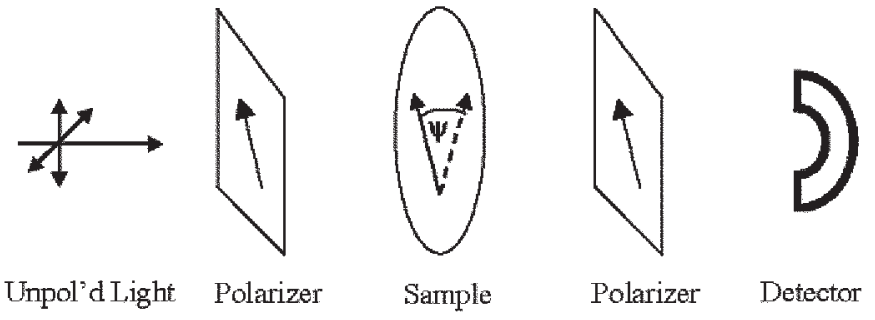

FIGURE 1 - Experimental setup for optical birefringence measurement.

based web process is a highly productivity process with good economics.

We present in this paper optical and color characteristics of TCF plastic-sheet polarizers and color-correction films produced by SMPA. Also, we present a retardation behavior of new clear retarders based on coating material C001. Samples of the retarders were produced by the Mayer-rod coating technique in laboratory scale. The samples of TCF C001 retarders were coated on glass substrate.

\section{Measurement methodology}

\subsection{Measurements of polarizing spectra}

Spectral measurements of TCF samples were performed with a Cary-500 spectrophotometer (Varian) under polarized light. The incident beam was polarized with a high-efficiency sheet polarizer. The spectrum of this polarizer was used as the baseline. We measured the optical transmission of the polarizer samples parallel and perpendicular to the polarizing axes of the polarizer $\left(T_{\mathrm{par}}\right.$ and $T_{\text {per }}$, respectively). We present the polarizing spectra with no substrate correction. The following parameters have been calculated:

transmission of a single polarizer in unpolarized light $T=\left(T_{p a r}+T_{p e r}\right) / 2$;

dichroic ratio $K d=\lg T_{\text {per }} / \lg T_{\text {per }}$;

contrast ratio $C R \approx T_{\text {par }} / 2 T_{\text {per }}$; $100 \%$.

polarizing efficiency $E p=\left(T_{p a r}-T_{p e r}\right) /\left(T_{p a r}+T_{p e r}\right) \times$

Color coordinates $a$ and $b$ were determined for single, two parallel, and two crossed polarizers at a known transmission. Polarizing parameters and color coordinates were calculated for the visible spectrum of $400-800 \mathrm{~nm}$ with CIE-photopic weighing and by considering the spectrum of illuminant C (or some LED).

\subsection{Measurement procedure for TCF retarders}

Retardation measurements were performed with a Cary500 spectrophotometer (Varian). The optical birefringence of films can be characterized via a technique reported earlier. ${ }^{21}$ We made spectral measurements of the transmission of the retardation film between parallel polarizers as a function of TCF sample orientation angle (Fig. 1).

Using the Jones matrix formalism, the transmission of the retarder between two parallel polarizers can be given as

\section{Transmittance, $\%$}

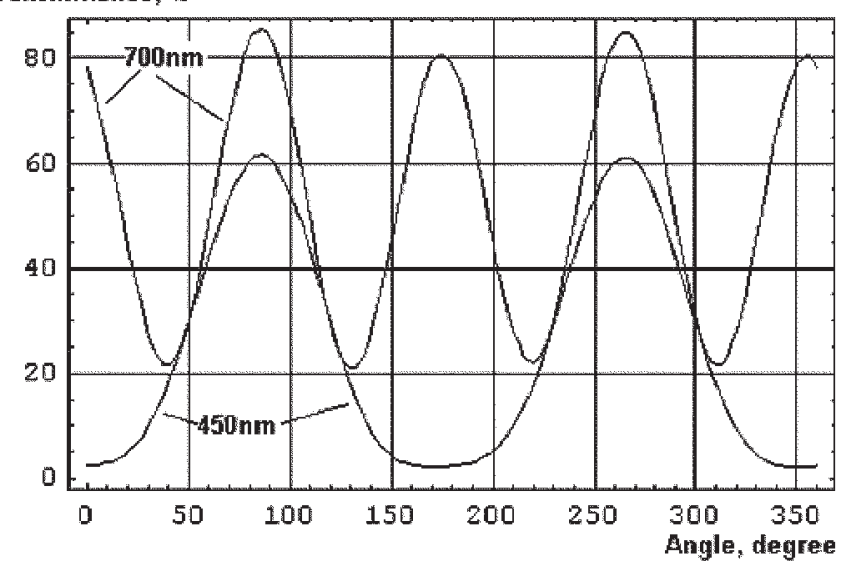

FIGURE 2 - Two typical dependencies of transmittance vs. rotation angle corresponding to 450- and 700-nm wavelengths for TCF Y104 retarder.

a function of the rotation angle of the retarder $\psi$ [the angle between the polarization axes of the analyzer and the director (coating direction) of the sample], wavelength $\lambda, \Delta n$, and the absorption.

$$
T=\frac{1}{2}\left|\cos ^{2} \psi e^{-i n_{0} 2 \pi h / \lambda}+\sin ^{2} \psi e^{-i n_{e} 2 \pi h / \lambda}\right|^{2} .
$$

Taking the first derivative with respect to the rotation angle and doing simple algebra, we can express $\Delta n$ as a function of the wavelength and polarized light transmission at the maxima $\left(T_{p a r}, T_{p e r}\right)$ and minimum $\left(T_{\min }\right)$ of the $T(\psi)$ function.

$$
\cos \left[2 \pi h\left(n_{o}-n_{e}\right) / \lambda\right]=\frac{T_{\min }-\sqrt{\left(T_{\text {par }}-T_{\min }\right)\left(T_{\text {per }}-T_{\min }\right)}}{\sqrt{T_{\text {par }} T_{\text {per }}}},
$$

where $h$ is the thickness of the film that we have measured with the Dektak ${ }^{3}$ ST system (Veeco). An example of the measured transmittance $v$ s. rotation angle is shown in Fig. 2.

\section{Products}

\subsection{TCF plastic optical films}

The first commercial applications of TCF technology are plastic-film polarizers, retarders, and color-correction films for the FPD market. Films were produced by slot-die coating. Optiva, Inc., has developed a polarizer plastic film set and a retarder plastic film set intended for use in $\mathrm{TN}$ displays that have fewer component layers, resulting in a lessexpensive substitute for conventional LCD polarizers and retarders. The new design avoids the conventional costly "cellulose triacetate (TAC) film sandwich" needed to protect the delicate PVA film with an optically neutral substrate. The optical plastic film set is composed of a low-reflection PET substrate coated with TCF, a PSA, and a release liner. The TCF TN transmissive film utilizes a sin- 
TABLE 1 - Polarizing characteristics and applications of Optiva film products coated on polymer PET base film.

\begin{tabular}{|c|c|c|c|c|c|c|c|c|c|}
\hline \multirow{2}{*}{$\begin{array}{l}\text { TCF Film } \\
\text { Product }\end{array}$} & \multirow{2}{*}{$\begin{array}{l}\text { PET Base } \\
\text { Film Type } \\
\text { and } \\
\text { Thickness, } \\
\mu \mathrm{m}\end{array}$} & \multirow{2}{*}{$\begin{array}{l}\text { TCF } \\
\text { Type }\end{array}$} & \multirow{2}{*}{$\begin{array}{l}\text { TCF } \\
\text { Thick } \\
\text { ness } \\
(\mathrm{nm})\end{array}$} & \multirow{2}{*}{$\begin{array}{l}\text { Illumi } \\
\text { nant }\end{array}$} & \multicolumn{3}{|c|}{ Transmission (\%) } & \multirow[t]{2}{*}{ Ep* } & \multirow[t]{2}{*}{ Application } \\
\hline & & & & & $\mathrm{T}$ & $\mathrm{H}_{0}$ & $\mathrm{H}_{90}$ & & \\
\hline TRMO13U & $\mathrm{U} 34,50$ & $\begin{array}{l}\text { N015 } \\
\text { neutral }\end{array}$ & 280 & $\mathrm{C}$ & 45.6 & 34.1 & 7.5 & 79.9 & \multirow[t]{2}{*}{ (1) TN reflector polarizer } \\
\hline RRM014U & DSM 50 & N015 & 280 & $\mathrm{C}$ & 45.6 & 34.1 & 7.5 & 79.9 & \\
\hline $\begin{array}{l}\text { TCM013U- } \\
1\end{array}$ & $\mathrm{U} 34,100$ & N015 & 200 & $\mathrm{C}$ & 51 & 37.9 & 15.3 & 65.3 & \multirow[t]{2}{*}{$\begin{array}{l}\text { (2) Clean-up polarizer or } \\
\text { contrast-enhancing film }\end{array}$} \\
\hline $\begin{array}{l}\text { TCM013U- } \\
2\end{array}$ & $\mathrm{U} 34,100$ & N015 & 135 & $\mathrm{C}$ & 57.9 & 41.7 & 25.5 & 49.1 & \\
\hline \multirow[t]{2}{*}{$\mathrm{NMH1} 13 \mathrm{U}$} & \multirow[t]{2}{*}{$\mathrm{U} 34,100$} & \multirow{2}{*}{$\begin{array}{l}\text { V008 } \\
\text { blue- } \\
\text { violet }\end{array}$} & \multirow[t]{2}{*}{240} & $\begin{array}{l}\text { LED } \\
589\end{array}$ & 42.0 & 30.1 & 5.2 & 84.0 & \multirow{2}{*}{$\begin{array}{l}\text { (3)Negative-mode } \\
\text { transmissive polarizer } \\
\text { for automotive designs }\end{array}$} \\
\hline & & & & $\begin{array}{l}\text { LED } \\
605\end{array}$ & 40.0 & 28.4 & 3.6 & 88.0 & \\
\hline TTM013U & $\mathrm{U} 34,100$ & N015 & 590 & $\mathrm{C}$ & 37.6 & 27.5 & 0.75 & 97.2 & $\begin{array}{l}\text { (4) TN transmissive } \\
\text { polarizer }\end{array}$ \\
\hline $\mathrm{CCF}-1$ & $\mathrm{U} 34,50$ & $\begin{array}{l}\text { Y104 } \\
\text { yellow }\end{array}$ & 410 & $\mathrm{C}$ & 88 & \multirow{2}{*}{\multicolumn{3}{|c|}{ n.a. }} & \multirow{2}{*}{$\begin{array}{l}\text { (5) Color-correction film } \\
\text { and contrast-enhancing } \\
\text { film for TFT monitors or } \\
\text { projection TV }\end{array}$} \\
\hline $\mathrm{CCF}-2$ & $\mathrm{U} 34,50$ & Y104 & 500 & $\mathrm{C}$ & 88 & & & & \\
\hline
\end{tabular}

* Polarizing efficiency.

gle, low-cost PET substrate as the external layer. Since this layer is outside the display optics, the birefringence properties are not relevant for most $\mathrm{TN}$ applications. While TAC film could be used in this design, PET provides a more durable substrate alternative that does not require hard coatings.

Optiva and Sony Magnetic Products of America (SMPA) produce TCF plastic-sheet polarizers and colorcorrection films by slot-die coating in one run. TCF products are listed below:

(1) TRMO13U/RRM014U is a sandwich-like "all-in-one" TN Reflector polarizer that consists of PET base film with a diffusive mirror covered with a planarization layer. Thin (280-310 nm thick) N015 layer is coated on the top of the planarization layer.

(2) Super-thin TCF clean-up polarizer (TCM013U) is available as thin as 200- and 135-nm coating. Nitto EG 1220 is a comparable product for this type of film. TCF clean-up polarizer would serve as a polarizing film with transmission of non-polarized light of more than $50 \%$. This product can also be used below a rear polarizer in TN TFT monitors or projection TV.

(3) Negative mode transmissive polarizer NMH113U is a $240-400-\mathrm{nm}$-thick TCF V008 on PET base film with a thickness of $100 \mu \mathrm{m}$. This product is intended for use in the automotive industry for backlights with a maximum emission at wavelength of 589, 605, and $624 \mathrm{~nm}$. In Table 1, an example is given for two backlights: 589 and $605 \mathrm{~nm}$.
(4) $\mathrm{TN}$ transmissive-mode polarizer TTM013U is a 580-nm-thick TCF N015 on PET base film with a thickness of $100 \mu \mathrm{m}$.

(5) Color-correction film CCF-1/CCF-2 (Table 1) is a film product consisting of TCF Y104 coated on a PET base film. The color-correction film and contrast-enhancing film are intended for use in TFT monitors or projection $\mathrm{TV}$.

The main parameters of Optiva film products are presented in Table 1.

\subsubsection{TCF color-correction films}

The efficiency of TCF polarizers depends on their thickness and the wavelength of maximum absorbance. This determines the choice of material or materials mixture. The polarizing spectrum of TCF N015 is presented in Fig. 3. This material effectively covers a relatively wide band from 450 to $800 \mathrm{~nm}$. The composition of initial LLC coating material can be optimized to provide specific color characteristics of resulting TCF polarizers and optical stacks composed of TCF polarizers. We use "a" and "b" color coordinates (the Hunter system, 1948), where "a" is the $\mathrm{red} /$ green coordinate $(+\mathrm{a}$ is red and $-\mathrm{a}$ is green), and " $\mathrm{b}$ " is the yellow/blue coordinate $(+\mathrm{b}$ is yellow and $-\mathrm{b}$ is blue). Smaller "a" and "b" numbers correspond to more neutral color hue (less colored). These "a" and "b" numbers are usually calculated with respect to a standard illuminant such as CIE Source C 


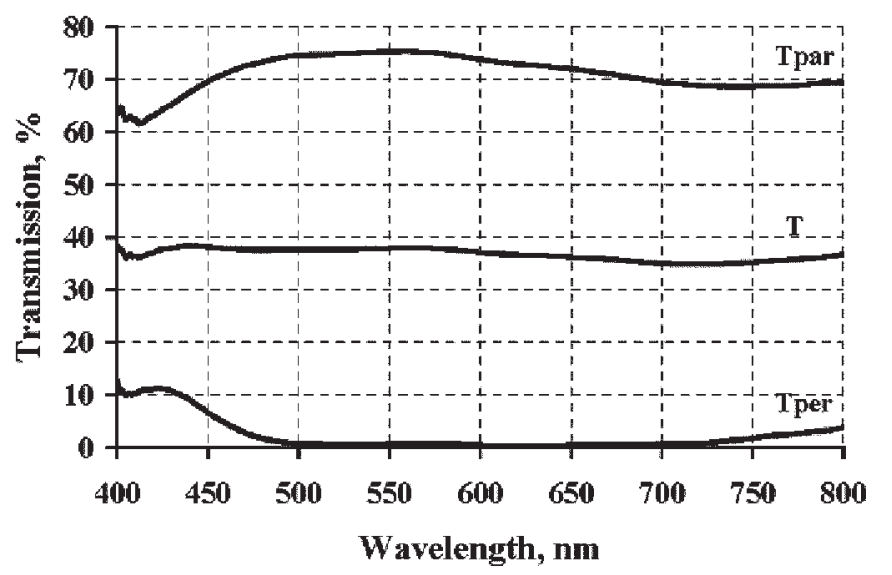

FIGURE 3 - Transmission of single TCF N015 polarizer, TCF thickness is $420 \mathrm{~nm}$.

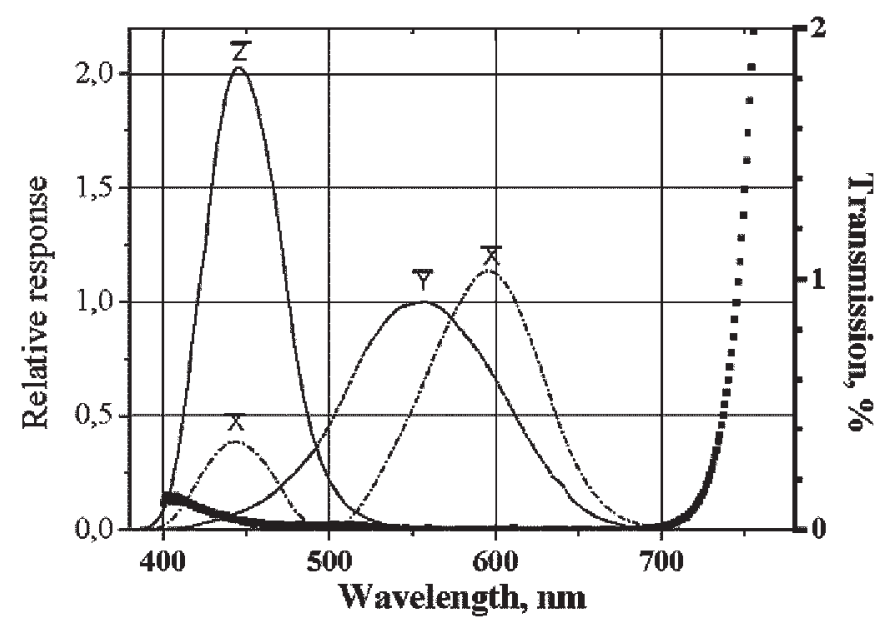

FIGURE 4 - Blue leakage of conventional polarizer (bold) and tristimulus values.

$$
a=\frac{17.5(1.02 X-Y)}{Y^{1 / 2}}, \quad b=\frac{7.0(Y-0.847 Z)}{Y^{1 / 2}} .
$$

Here $X, Y$, and $Z=1931$ CIE tristimulus values (taken in percent). For TCF polarizers (e.c. N015), the color coordinates appear to be dependent on TCF thickness.

The transmission spectra of perpendicular polarization $T_{\text {per }}$ measured for neutral conventional sheet NittoDenko EG1224DU polarizer and Optiva TCF polarizers reveal some leakage in the blue spectral region that is called the "blue leakage problem." The transmission spectrum of perpendicular polarization of a conventional high-efficiency

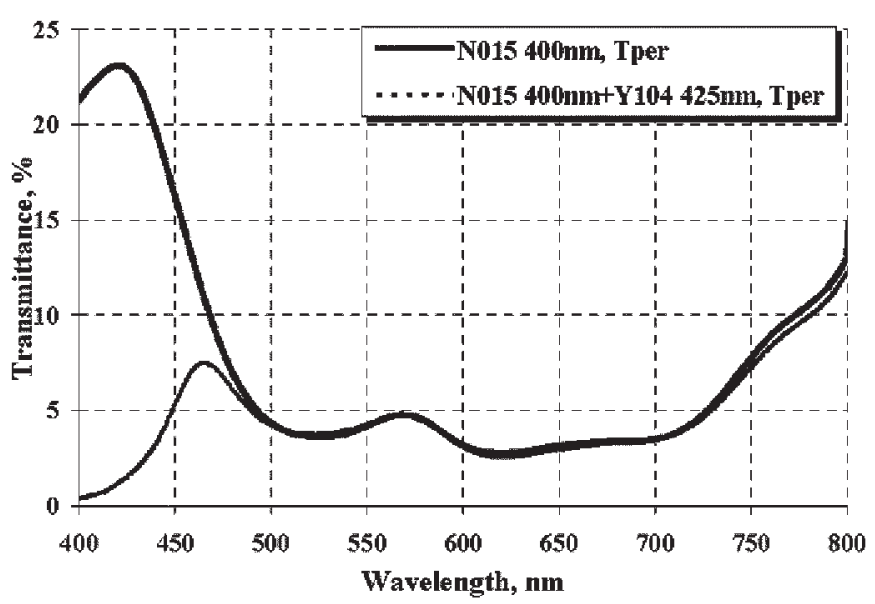

FIGURE $5-T_{\text {per }}$ spectra of TCF N015 (400 nm thickness) and TCF N015 (400 nm thickness) + TCF Y104 (425 nm thickness).
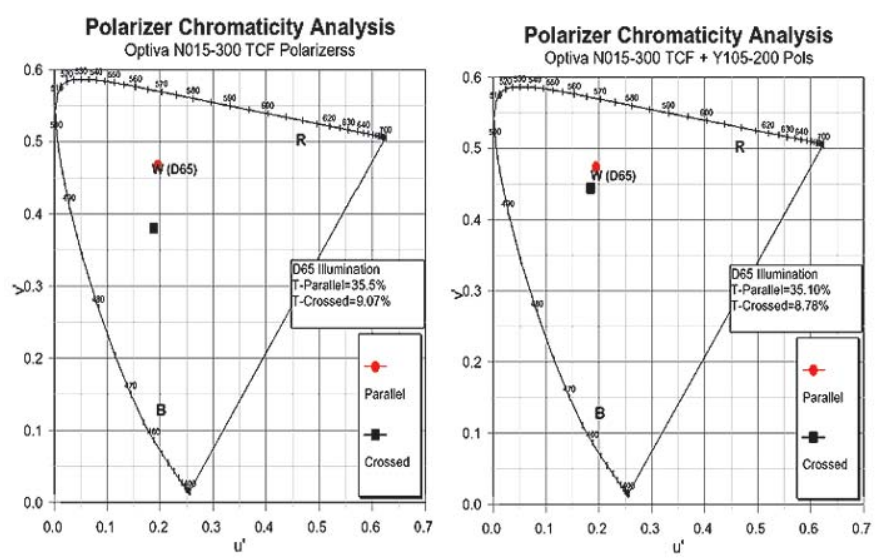

FIGURE 6 - Color coordinates of TCF N015 coatings on glass (left) and TCF N015 with additional Yellow TCF Y104 color-correction coating (right).

polarizer is shown in Fig. 4 (thick curve). The transmission spectrum of TCF N015 Optiva polarizer in crossed state $T_{\text {per }}$ is shown in Fig. 3.

We developed several TCF materials, in particular TCF Y104 (Yellow), to solve the blue leakage problem. These materials called color-correction films (CCF) essentially absorb light in the violet and near-UV wavelength regions. Transmission of CCF N015 + Y104 in the crossed state is shown in Fig. 5 (solid curve for single N015 polarizer and dashed curve for N015 + Y104).

Table 2 and Fig. 6 demonstrate how the color coordinates of the Optiva TCF N015 polarizer and conventional

TABLE 2 - Color deviation $=\left(a^{2}+b^{2}\right)^{0.5}$ from neutral color for TCF N015 (400 nm thickness) and N015 with additional coating of TCFY104 (425 nm thickness).

\begin{tabular}{|c|c|c|c|c|c|c|c|c|}
\hline \multirow{2}{*}{$\begin{array}{l}\text { Illumi } \\
\text { nant }\end{array}$} & \multicolumn{2}{|c|}{ Opened State } & \multicolumn{2}{|c|}{ Crossed State } & \multicolumn{2}{|c|}{ Opened State } & \multicolumn{2}{|c|}{ Crossed State } \\
\hline & $\begin{array}{l}\text { Optiva } \\
\text { N015 }\end{array}$ & $\begin{array}{l}\text { Optiva } \\
\text { N015+ } \\
\text { Y104 }\end{array}$ & $\begin{array}{l}\text { Optiva } \\
\text { No1s }\end{array}$ & $\begin{array}{l}\text { Optiva } \\
\text { N015+ } \\
\text { Y104 }\end{array}$ & $\begin{array}{l}\text { Nitto } \\
\text { Denko } \\
\text { EG1224DU }\end{array}$ & $\begin{array}{l}\text { Nitto } \\
\text { Denko } \\
\text { EG1224DU } \\
\text { +Y104 }\end{array}$ & $\begin{array}{l}\text { Nitto } \\
\text { Denko } \\
\text { EG1224DU }\end{array}$ & $\begin{array}{l}\text { Nitto Denko } \\
\text { EG1224DU } \\
+ \text { Y104 }\end{array}$ \\
\hline $\mathrm{C}$ & 2.9 & 11.2 & 32.0 & 2.6 & 6.0 & 14.6 & 2.4 & 0.4 \\
\hline CCLF & 10.9 & 3.9 & 63.7 & 5.3 & 7.9 & 5.3 & 95.6 & 5.8 \\
\hline
\end{tabular}




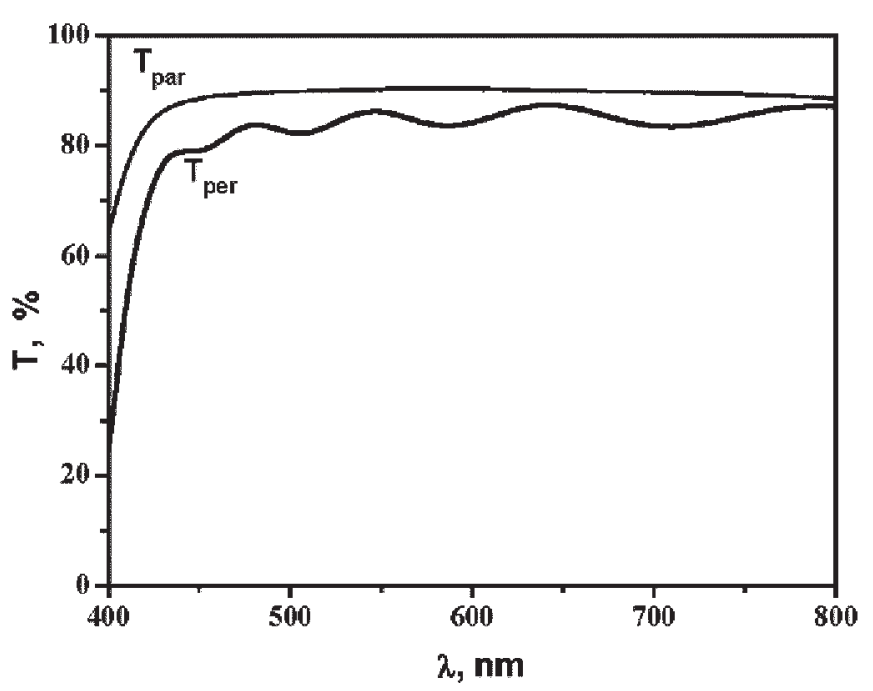

FIGURE 7 - Transmission spectra for TCF C001. Incident beam is linearly polarized perpendicular and parallel to coating direction.

sheet polarizer (Nitto-Denko EG1224DU polarizer) can be shifted towards neutral hue using an additional layer of color-correction film TCF Y104. Color deviation is determined as $\left(\mathrm{a}^{2}+\mathrm{b}^{2}\right)^{0.5}$. The TCF thickness is $400 \mathrm{~nm}$ for TCF N015 and $425 \mathrm{~nm}$ for TCF Y104.

We estimated the optical performance and color coordinates of Optiva TCF N015 and conventional high-efficiency polarizer EG1224DU by using Optiva CCF TCF Y104 with illuminant $\mathrm{C}$ and illuminant CCLF, which is particularly important for TFT applications.

The shift of color coordinates towards neutral for the crossed state of EG1224DU + Y104 compared with the one for EG1224DU is not as strong for illuminant C, but is large for illuminant CCLF. Compensation of the color distortion at a viewing angle different from $90^{\circ}$ is also of great importance. The color of the sandwich structure in the open state becomes slightly turquoise (bluish-greenish) using a CCLF backlight and greenish-yellowish using illuminant C.

For comparison, the color for EG1224DU in the crossed states is purple and deep blue when calculated with illuminants $\mathrm{C}$ and CCLF, respectively. The color for EG1224DU in open states is greenish-yellowish or purplish, respectively. The color deviation from neutral becomes small for both illuminants by adding a CCF Y104 layer.

The color-correction film CCF-1/ CCF-2 (see Table 1) is a film product consisting of TCF Y104 coated on PET base film. The transmission of CCF (i.e., transparency in the visible region, 400-700 $\mathrm{nm}$ ) with CIE photopic weighing, assuming that the spectrum of illuminant $\mathrm{C}$ is about $88-89 \%$

\subsection{TCF retarders based on C001 derivatives}

We developed a TCF retarder based on clear C001 coating material. The transmission spectra of optically anisotropic film measured parallel and perpendicular to the alignment direction are shown in Fig. 7. The TCF produced from this

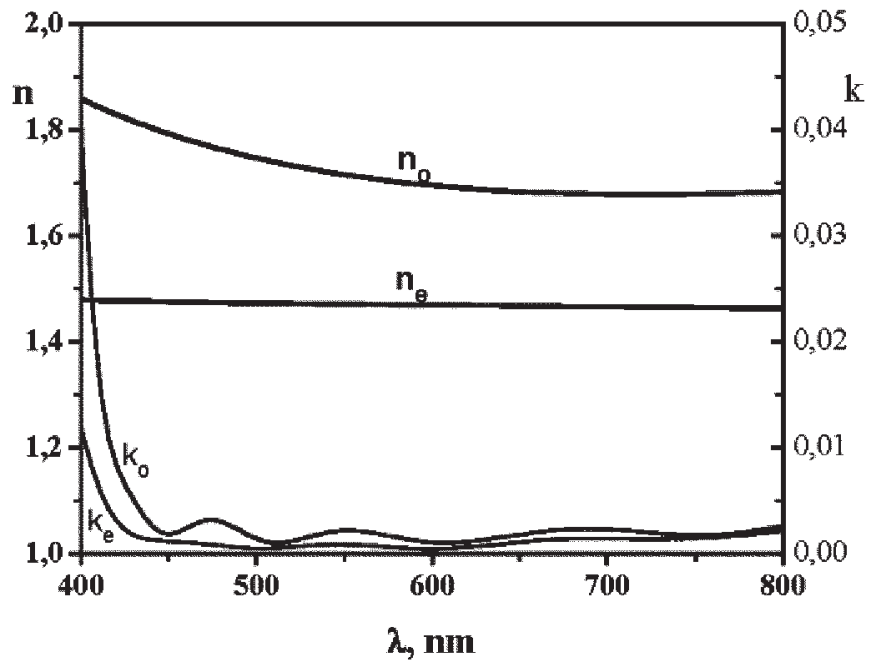

FIGURE 8 - Refraction indices $\left(n_{\mathrm{O}}, n_{\mathrm{e}}\right)$ and absorption coefficients $\left(k_{\mathrm{O}}\right.$, $k_{\mathrm{e}}$ ) for TCF C001 measured parallel and perpendicular to the coating direction.

material has very low adsorption coefficients in a visible spectral range $(\lambda>400 \mathrm{~nm})$ and only absorbs in the UV spectral region.

High optical anisotropy (up to $\Delta n=0.35$ in the visible spectral range) and high transparency (extinction coefficients are on the order of $10^{-3}$ ) of the films (Fig. 8) allow for the design of high-efficiency multilayer interference reflective polarizers. Refractive indicies and absorption coefficients were calculated by measuring the polarized transmission at $0^{\circ}$ and $30^{\circ}$ s-reflectance in polarized light. Together, with the known thickness of the samples, the data enable the determination of the refractive indices of the uniaxial TCF film coated on thick glass substrate based on a $4 \times 4$ matrix method.

Multilayer reflective interference polarizers allow for the design of LCD backlights with more than $50 \%$ conversion of the non-polarized light by one polarization. The main advantage of TCF-based reflective polarizers is their effective use of light-wave interference for high-efficiency reflectance of one polarization. The design of interference polarizers is possible because of the thinness (quarter wavelength) of the anisotropic TCF coating. Conventional reflective polarizers use stretched polymer birefringent layers ${ }^{22}$ that are produced by extrusion. Interference polarizers promise a much higher reflectivity and dichroic ratio than thicker reflective polymer films.

The expected efficiency of multilayer TCF-based reflective polarizers was demonstrated by simulation. We considered a 20-layer structure consisting of 10 TCF C001 layers with a thickness of $74 \mathrm{~nm}$ that were alternated with 10 layers of optically isotropic lacquer with a layer thickness of $92 \mathrm{~nm}$. The thickness of each layer was chosen to be equal to that of a quarter-wave plate at $550 \mathrm{~nm}$. The TCF refraction indices $n_{\mathrm{o}}$ and $n_{\mathrm{e}}$ were 1.72 and 1.47 respectively. TCF C001 absorption coefficients $k_{\mathrm{o}}$ and $k_{\mathrm{e}}$ were 0.0025 and 0.001 , respectively. The lacquer refraction index was equal to 1.47. We assume here for sake of simplicity that the 


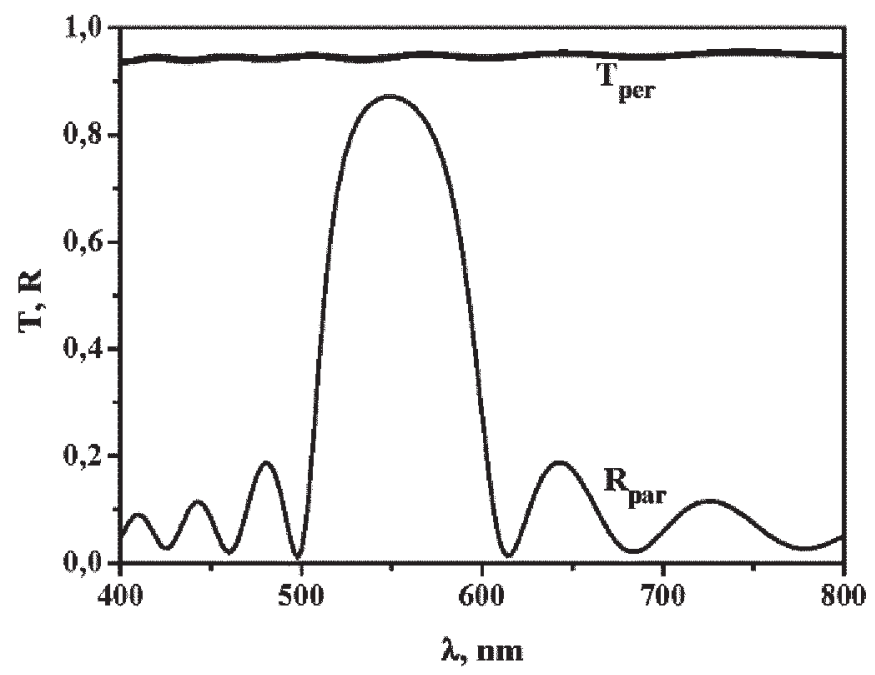

FIGURE 9 - Calculated transmission spectrum of perpendicular component and reflection spectrum of parallel component of normally incident light for a modeled multilayer reflective polarizer.

refraction and absorption indices are not dependent on wavelength. The transmission spectrum of the perpendicular component of the incident non-polarized light and the reflection spectrum of the parallel component that were calculated according to the model, are shown in Fig. 9. The simulation shows that up to $89 \%$ of the non-polarized light could be converted to linearly polarized light at $550 \mathrm{~nm}$ using this reflective polarizer.

A reflective polarizer that is effective over the entire visible spectral range can be designed as a combination of several multilayer packages (cavities) similar to those
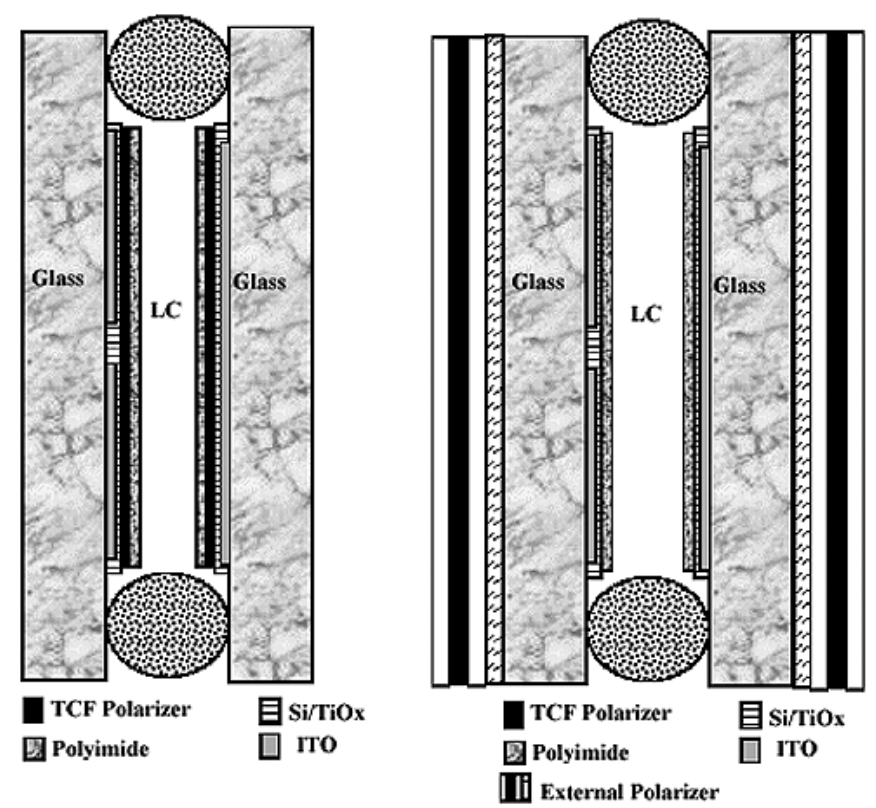

FIGURE 10 - Liquid-crystal cells with internal polarizer: TCF is coated inside the LC cell to form an internal polarizer (right); the cell with plastic iodine polarizers laminated on the outside glass surfaces (left).

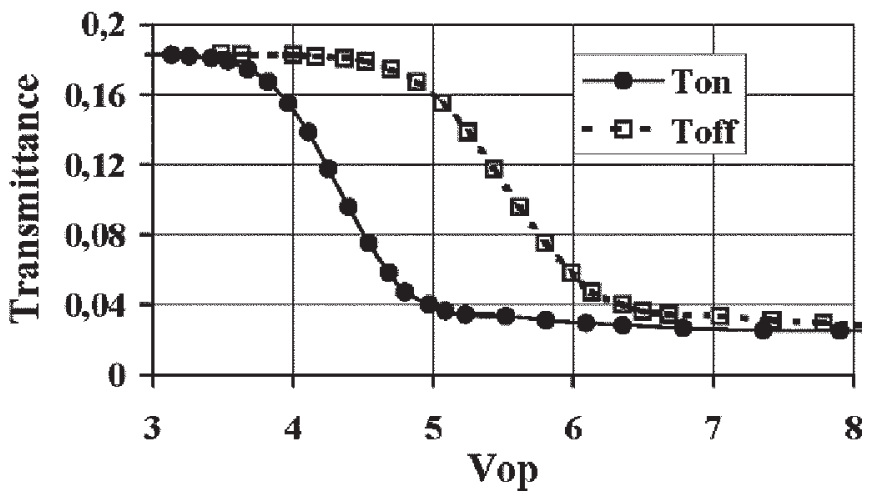

FIGURE 11 - T-V curves for 1/16-duty STN-LCD.

described above and be responsible for different regions of the visible spectrum.

\subsection{TCF internal polarizers}

Sub-micron-thick TCF polarizers provide new opportunities for LCD designs with interior applications of TCF polarizers. ${ }^{23}$ Unlike typical transmissive TN- or STN-LCD optical stacks with plastic polarizers laminated on the outside glass surfaces (Fig. 10, left), TCF polarizers can be applied inside the LCD cell (Fig. 10, right), and the overall LCD thickness can be significantly reduced.

TCF internal polarizers applied inside the glass LCD cell can withstand high-temperature operations during LCD manufacturing, including polyimide baking processes at $150-230^{\circ} \mathrm{C}$ and hot press sealing. The application of TCF as an internal polarizer allows LCD manufacturers to avoid the risks of delamination, bubbling, and color degradation that are typical for conventional external polarizing films during LCD manufacturing and exploitation under harsh environmental conditions.

We produced and characterized prototype LCD cells with internal TCF polarizers.

Transmittance $v s$. operating voltage $\left(\mathrm{T}-\mathrm{V}_{\mathrm{op}}\right.$ curves) and contrast ratio $v s$. operating voltage $\left(\mathrm{CR}-\mathrm{V}_{\text {op }}\right.$ curves $)$ for

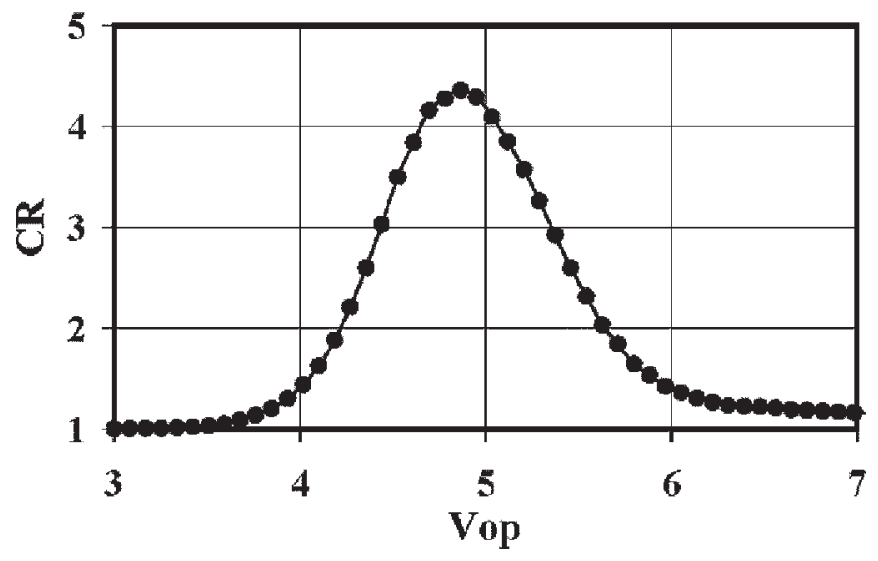

FIGURE $12-$ CR-V $_{\text {op }}$ curves for 1/16-duty STN-LCD. 

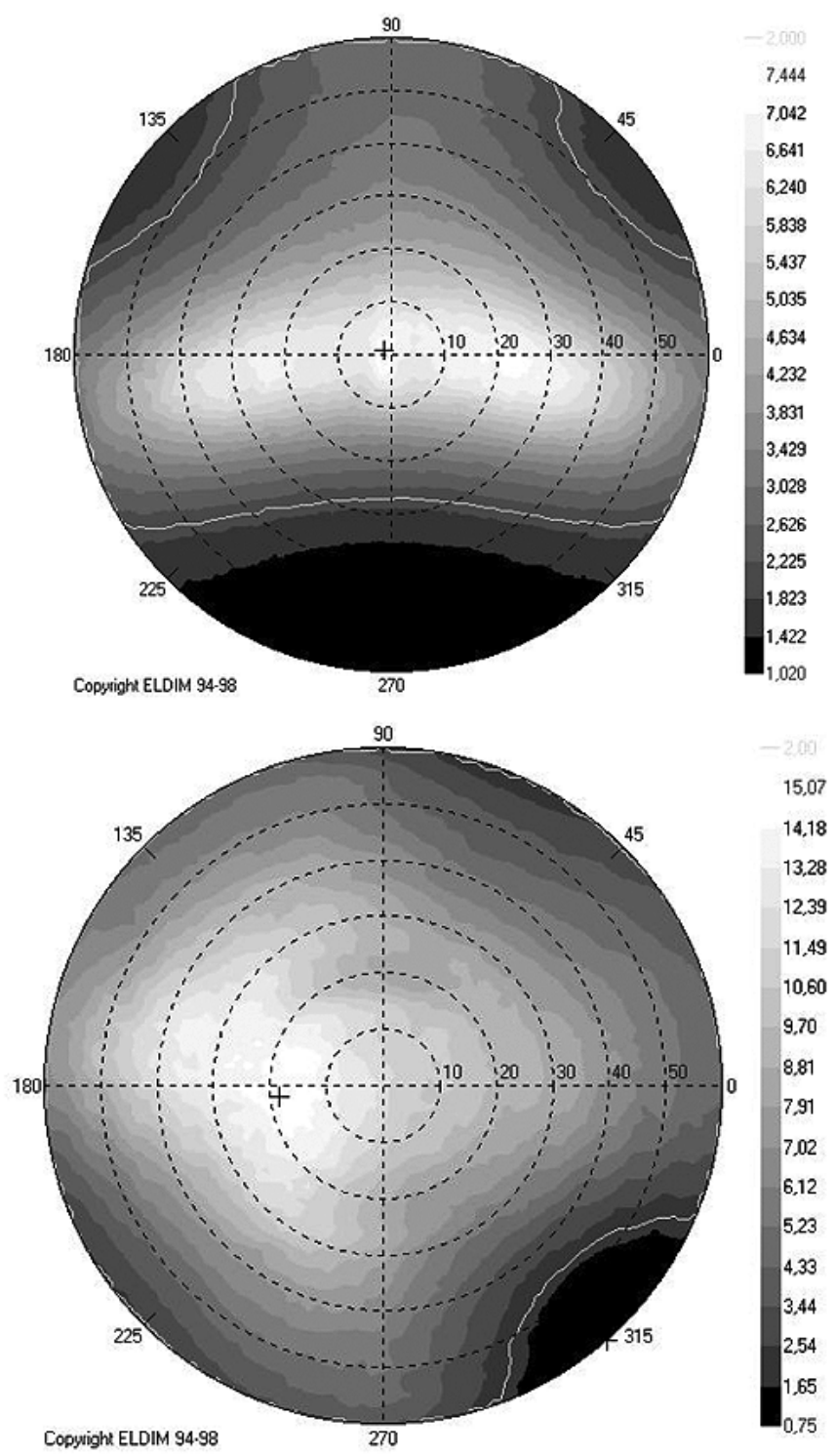

FIGURE 13 - Isocontrast plots of 1/4-duty TN-LCD: conventional high-durability polarizers (top) and V008 internal (bottom) transmissive mode, backlight white LED.

1/16-duty LCDs are presented in Figs. 11 and 12, respectively. One can see that electro-optical responses for LCDs with internal polarizers have the same shape as those with external polarizers. Thus, such TN- and STN-LCD cells can be driven at the same operating voltage as the LCD with conventional high-durability dye-type external polarizes, while providing higher contrast values.

Figures 13 and 14 and 15 show isocontrast plots and their cross sections, respectively, measured for LCDs with highly durable conventional polarizers (Fig. 10, left) and LCDs with internal TCF polarizers (Fig. 10, right). These plots demonstrate that the absolute values of the contrast ratio of internal TCF polarizes is somewhat higher than that for LCDs with external highly durable film polarizers. At the same time, the shape of the isocontrast plots of the LCD with internal TCF polarizers is more symmetrical, which means a wider viewing-angle cone.

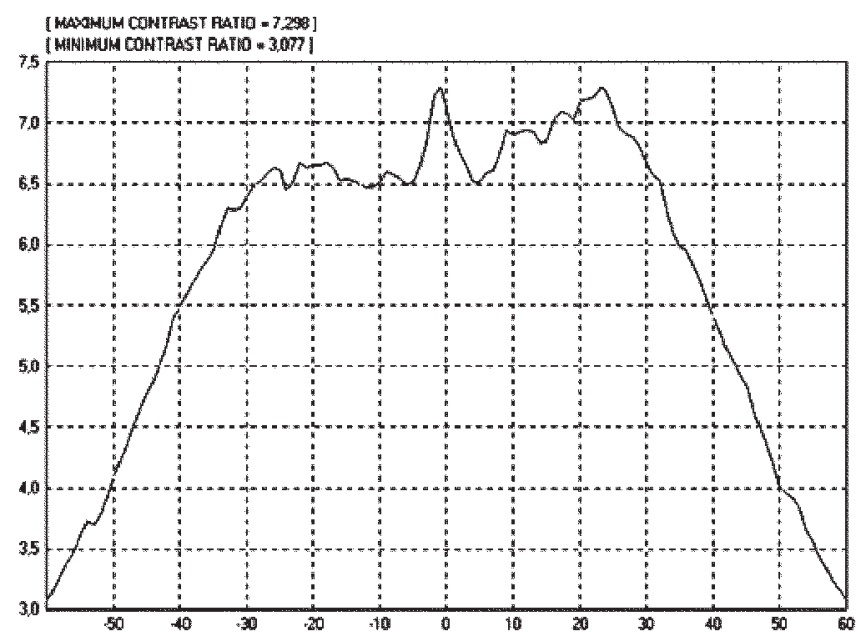

a)

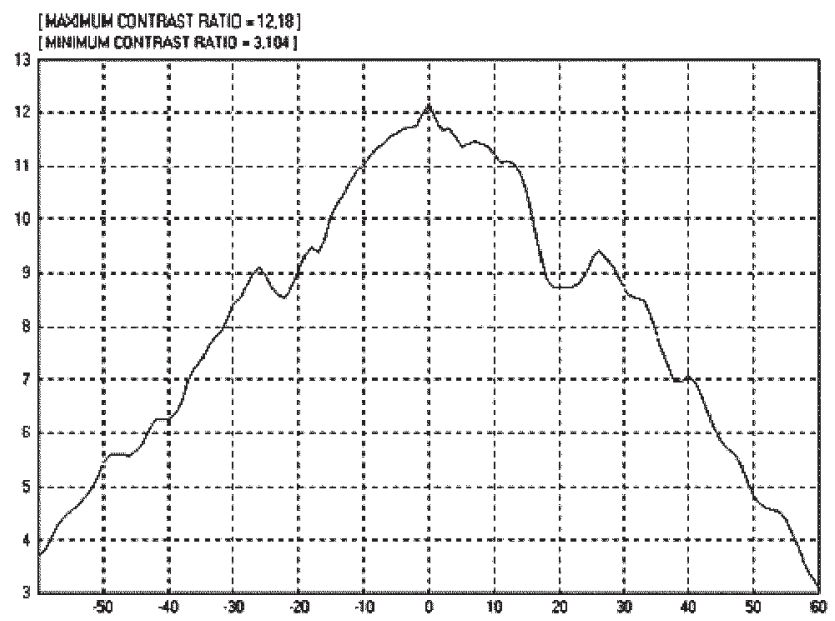

b)

FIGURE 14 - Cross section of 1/4-duty TN-LCD isocontrast diagram. (a) Conventional high-durability polarizers and (b) V008 TCF internal polarizer. Transmissive, white LED, $\varphi=0-180$.

Tecdis S.p.A. (Italy) - the leading European LCD manufacturer - uses TCF technology for the manufacture of STN-LCD cells with internal polarizers for automotive applications. ${ }^{24}$ The characteristics of the displays found on the Tecdis S.p.A. web site are as follows:

- maximum ambient temperature, still readable, higher than $100^{\circ} \mathrm{C}$,

- viewing angle larger than $\pm 40^{\circ}$,

- a contrast ratio that is more the two times that of typical STN displays at the same duty cycle.

The field life of the product is more than any standard: no less than 20 years.

Cooperation between Tecdis S.p.A., Nakan Corp., and Optiva, Inc., allowed for the development of manufacturing processes and for the start of LCD mass production based on TCF technology.

The important benefits related to the optical performance are:

- viewing angle improvement; 


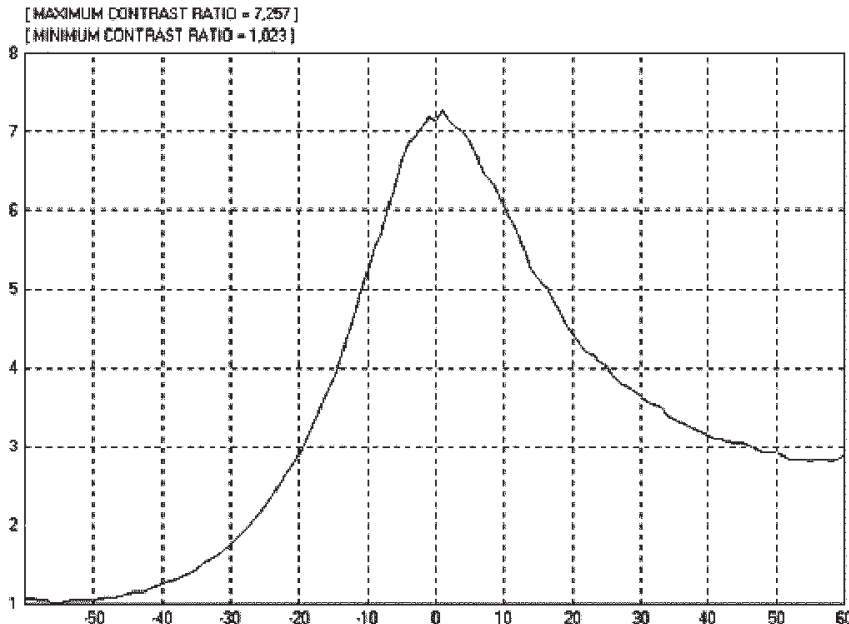

a)

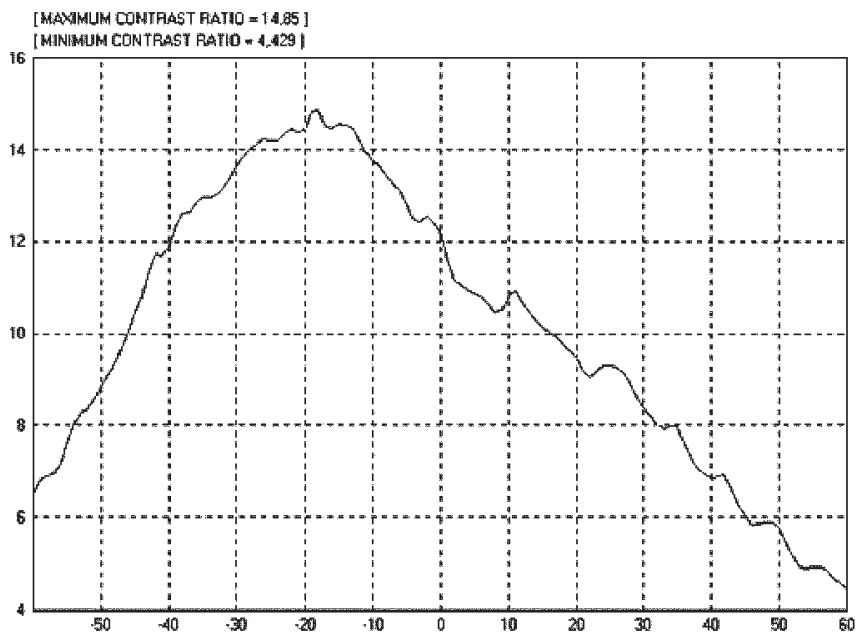

b)

FIGURE 15 - Cross section of 1/4-duty TN-LCD isocontrast diagram. (a) Conventional high-durability polarizers and (b) V008 TCF internal polarizers. Transmissive, white LED, $\varphi=90-270$.

- transmittance improvement;

- parallax error reduction;

- LCD thickness reduction;

- the possibility of compensating the backlight spectrum by different dyes;

- high-temperature resistance

and to the reliability are:

- no scratches on the video;

- no degradation in aggressive chemical environments;

- no degradation in high-humidity environments

in respect to standard LCD technology that uses plastic polarizer films.

\section{Conclusions}

1. TCF plastic optical films produced by Sony Magnetic Products of America and Optiva, Inc., pre- sent a lower cost alternative to conventional polarizing films currently on LCD market.

- TN reflector polarizer RRM014U is an "all-in-one" polarizing film that can be incorporated into today's reflective designs.

- Negative-mode transmissive polarizer NMH113U is intended for a variety of automotive LCD designs.

- Super-thin TCF clean-up polarizer TCM013U offers contrast improvement, and CCF offers both contrast and color improvement for current optical devices/designs.

- TN transmissive-mode polarizer TTM013U is a lowcost component for transmissive TN-LCD designs.

2. TCF C001 material has low absorption in the visible spectral range and good retardation properties. TCF C001 opens up an avenue for interference multilayer reflective polarizer design and manufacturing.

3. Advanced LCD designs with TCF internal polarizers show advantages in viewing angle and environmental stability.

\section{Acknowledgments}

The authors acknowledge Dr. A. Zhukov for providing the model simulation of multilayer reflective polarizers and Dr. E. Neburchilova for help in preparing this paper for publication.

\section{References}

1 Method and Materials for Thermostable and Lightfast Dichroic Light Polarizers, U.S. Patent 5739296 (1998).

2 Dichroic Light Polarizers, U.S. Patent 6049428 (2000).

3 Dichroic polarizer and method for making the same, U.S. Patent 6563640 (2003).

4 Anisotropic films based on sulfoderivatives of phenanthro- $9^{\prime}, 10^{\prime}: 2,3-$ quinoxaline and lyotropic liquid crystal systems and method for making, U.S. Patent 6583284 (2003).

5 Liquid crystal display and method, WO 97/39380 (1997).

6 Method for thermostable and lightfast dichroic light polarizers, U.S. Patent 6174394 (2001).

7 A Dembo, A Ionov, P Lazarev, A Manko, and V Nazarov, "Lyotropic Dye-water Mesophases formed by Rod-like Supramolecules," Molecular Materials 14(4), 275-290 (2001).

8 S Remizov, A Krivoshchepov, V Nazarov, and A Grodsky, "Rheology of the lyotropic liquid crystalline material for thin film polarizers," Molecular Materials 14, 179 (2001).

9 P Yeh and M Paukshto, "Molecular crystalline thin-film E-polarizer," Molecular Materials 14, 1-19 (2001).

$10 \mathrm{Yu}$ A Bobrov, "Dependence of the anisotropic absorption coefficient on the thickness of molecularly oriented organic dye films," J Opt Technol 66, 547-549 (1999).

11 Y Bobrov and V Novak "Determination of Anisotropic Complex Refractive indices of Thin Film E-polarizers," Molecular Materials 14 21-31 (2001).

12 Y Bobrov, P Lazarev, D McMurtry, and S Remizov, "Incorporation of Optiva Polarizers in LCD Production Line," SID Intl Symp Digest Tech Papers, 639-641 (2001).

13 Y Bobrov, L Blinov, L Ignatov, G King, P Lazarev, V Nazarov, N Ovchinnikova, and S Remizov, "Environmental and optical testing of Thin Crystal Film ${ }^{\mathrm{TM}}$ polarizers," J SID 11/1, 63-70 (2003).

14 T Sergan, T Schneider, J Kelly, and O D Lavrentovich, "Polarizingalignment layers for twisted nematic cells," Liq Cryst 27, 567-572 (2000). 
15 T Sergan and J Kelly. Negative uniaxial films from lyotropic liquidcrystalline material for liquid-crystal display applications," Liq Cryst 27, 1481-1484 (2000).

16 L Fennell, P Lazarev, S Ohmura, and M Paukshto, "Thin Crystal Film Polarizers ${ }^{\mathrm{T} M}$," Proc 21st Intl Display Research Conf, 601-603 (2001).

17 Y Bobrov, L Fennell, P Lazarev, M Paukshto, and S Remizov, "Manufacture of a Thin-Film LCD," J SID 10/4, 317-321 (2002).

18 Y Bobrov, L Fennel, T Ganpule, P Lazarev, and S Ohmura, "Manufacturing and Coating Equipment Development for Thin Crystal Film Printing," Proc 9th Intl Display Workshops, 405-408 (2002).

19 P Lazarev, V Nazarov, N Ovchinnikova, and S Remizov, "Printed Optical Components for Liquid Crystal Displays, 12th Intl Symp Advanced Display Technologies: Basic Studies of Problems in Information Display (FLOWERS '2003), 186-189 (2003).

20 E G Gutoff and E D Cohen, Coating and Drying Defects: Troubleshooting Operating Problems (Wiley-Interscience, London, 1995), p. 287.

21 P Lazarev, N Ovchinnikova, and M Paukshto "Submicron Thin Retardation Coating," SID Intl Symp Digest Tech Papers, 571-573 (2001).

22 D L Wortman, "A Recent Advance in Reflective Polarizer Technology," Research Conf. and International Workshops on LCD Tech. and Emissive Tech., M98-M106 (1997).

23 M Paukshto and L Silverstein, "Viewing Angle Enhancement of TNLCD Using E-type Polarizers," SID Intl Symp Digest Tech Papers, 902-905 (2001).

24 www.tecdis.com/pages/news.htm.

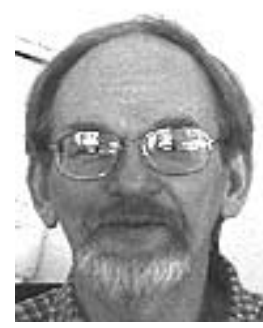

Yury A. Bobrov graduated from the physics department of Kazan State University in 1971 . He received his Ph.D. degree from Moscow Chemical Physics Institute, Russian Academy of Sciences in 1985. Since 1985, he has been developing coating methods of thin oriented films based on dye lyotropic liquid crystals and studying their properties. He is currently a senior researcher at Optiva, Inc. His current focus is on the application of TCFs in the LCD industry. He is an author of more than 20 papers and 10 inventions.

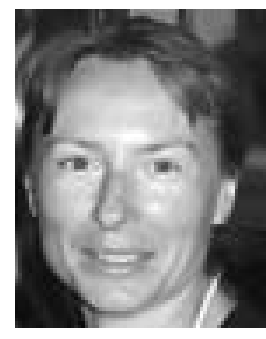

Olga E. Kuchenkova received her Ph.D. degree in polymer chemistry from Moscow State University in 1998. She has research experience in fields of interpolyelectrolyte complex formation, lipid bilayer-polycation interaction and lyotropic liquid crystals. She has published three scientific papers. She is currently a senior researcher of Optiva Technology Ltd., Russia. Her current work is devoted to development of multilayer TCFbased structures.

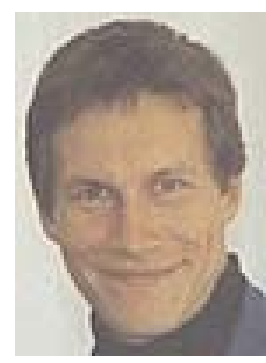

Mikhail B. Kouznetsov received his Ph.D. degree in solid physics from Moscow Engineering-Physicist Institute (Technical University) in 2001. In 2001 he joined Optiva, Inc. He is currently a senior engineer of Optiva-Technology, Ltd., Russia. He has published 20 scientific papers. His research areas include surface physics and optics.

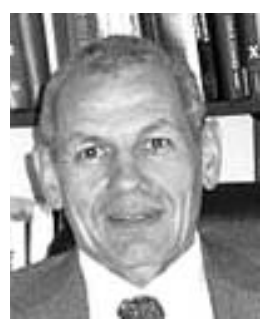

Pavel I. Lazarev received his M.S. degree in crystallography from Moscow State University and his Ph.D. (Chemistry) and Dr. Sci. (Biophysics) degrees from the Russian Academy of Sciences. He has published more than 100 scientific papers and has authored more than 30 inventions. His research areas include material research, crystallography, and biophysics.

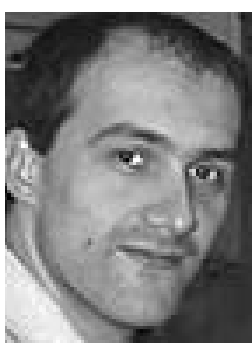

Andrew A. Manko received his M.D. in chemistry from Moscow State University in 1997. He has research experience in fields of Liquid crystalline polymers, liquid crystal-substrate interaction and lyotropic liquid crystals. He has published three scientific papers. He is currently a researcher of Optiva Technology Ltd., Russia. His current work is devoted to development of LLC compositions and coating of TCF structures.

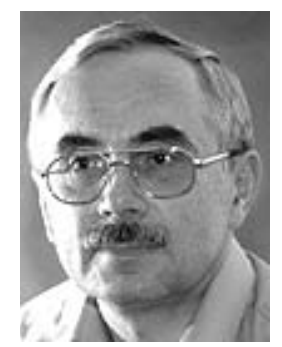

Victor V. Nazarov received his Ph.D. and Dr. Sci. degrees from Mendeleyev University of Chemical Technology of Russia. Since 1996, he has been a Professor at Mendeleyev University of Chemical Technology of Russia, and Head of the colloid chemistry department. In 1998, he joined Optiva, Inc. Since 2002 he has been Vice President of Optiva Technology, Ltd. (Russia). He has published more than 100 scientific papers. His research areas are surface phenomena and disperse (colloidal) systems.

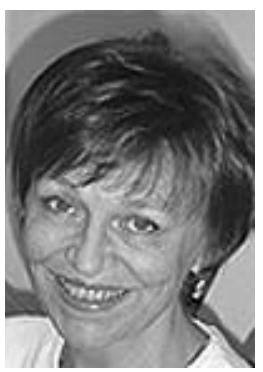

Natalya A. Ovchinnikova received her M.S. from the Moscow State Institute of Electronic Techniques in 1975. Since 1976, she has worked in the field of organic thin films. She is currently a senior scientist at Optiva, Inc. Her research areas include materials research and crystallography of thin crystal films. She has authored more than 10 scientific papers and two inventions.

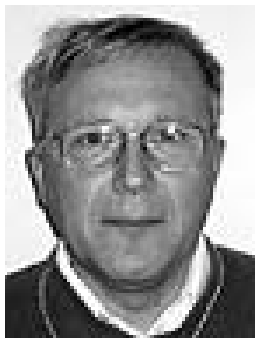

Michael V. Paukshto received Ph.D. and Dr. Sci. from St. Petersburg University. From 1981 to 1994 he served as a Staff Senior Scientist at Smirnov Institute of Mathematics and Mechanics at St.-Petersburg and later on as a Staff Senior Scientist at Institute for Mechanical Engineering Problems, Russian Academy of Science. From 1994 to 1998 he is a Professor at State Maritime Technical University at St.-Petersburg, as well as a Visiting Research Scientist at Institute for Mechanics and Materials at the University of California at San Diego. Since 1998, he is a Senior Scientist at Optiva, Inc. Published more than 100 scientific papers and five monographs. His research area is Mechanics of materials, Optics and Computational engineering. 


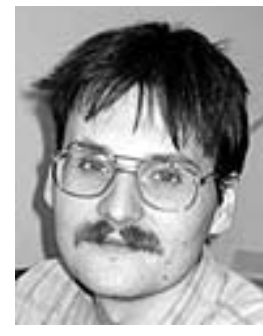

Pavel P. Protsenko received his Ph.D. degree in colloid chemistry from Moscow State University in 2002. He has research experience in fields of LB films formation, high temperature wetting and liquid metal corrosion. He has published 10 scientific papers. He is currently a researcher of Optiva Technology Ltd., Russia. His current work is devoted to optical characterization of TCF and development of multilayer TCF-based structures.

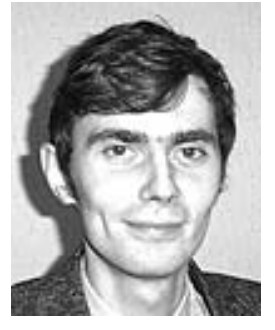

Sergey V. Remizov received his Ph.D. degree in colloid chemistry from Moscow State University in 1996. In 1999, he joined Optiva, Inc. He is currently a senior engineer of Optiva Technology, Ltd., Russia. He has published 25 scientific papers. His research areas include surface chemistry and the rheology of structured dispersions and lyotropic liquid crystals. 